\title{
High Aitken Nucleus Concentrations Above Cloud Tops in the Arctic
}

\author{
by \\ Timothy J. Garrett* and Peter V. Hobbs \\ Atmospheric Sciences Department, University of Washington, Seattle, Washington. \\ and \\ Lawrence F. Radke \\ National Center for Atmospheric Research, Boulder, Colorado.
}

\begin{abstract}
Submitted for publication as a NOTE to J. Atmos. Sci. (for Special Issue on Global Aerosol Climatology): 12 December 2000

Revised manuscript submitted: 6 April 2001
\end{abstract}

Corresponding author: Peter V. Hobbs

University of Washington

Department of Atmospheric Sciences

Box 351640

Seattle, WA 98195-1640

Tel: (206) 543-6027

Fax: (206) 685-7160

E-mail: phobbs@atmos.washington.edu

\footnotetext{
${ }^{*}$ Now at Atmospheric and Oceanic Sciences Program, Princeton University
} 


\title{
High Aitken Nucleus Concentrations Above Cloud Tops in the Arctic
}

\author{
Timothy J. Garrett ${ }^{*}$ and Peter V. Hobbs \\ Atmospheric Sciences Department, University of Washington, Seattle, Washington.
}

Lawrence F. Radke

National Center for Atmospheric Research, Boulder, Colorado.

\begin{abstract}
Airborne measurements in the Arctic in spring show large increases in the concentrations of particles with diameters below about $0.1 \mu \mathrm{m}$ just above the tops of stratus clouds when the water vapor mixing ratio is relatively high in these regions. Low temperatures and low particle surface areas may also favor the appearance of these particles. Particles produced above stratus clouds could be a widespread source of aerosol in the Arctic.
\end{abstract}

\footnotetext{
${ }^{*}$ Now at Atmospheric and Oceanic Sciences Program, Princeton University
} 


\section{Introduction}

Field measurements in middle latitudes have shown that, under appropriate conditions, large concentrations of small (Aitken nuclei) particles can be present above the tops of stratiform clouds (Hegg et al. 1990) and in the vicinity of convective clouds (Radke and Hobbs, 1991; Hudson and Frisbie 1991; Hudson 1993; Perry and Hobbs 1994). It has been suggested that particles generated near the tops of large convective towers in the tropics are transported poleward, sink in the sub-tropics, and thereby supply large numbers of particles to the subtropical troposphere (Raes et al. 1993).

Here we report on measurements of high Aitken nucleus concentrations above the tops of stratus clouds in the Arctic, and the conditions that appear to favor their formation.

\section{Instrumentation}

All of the measurements to be described were obtained aboard the University of Washington's (UW) Convair-580 research aircraft in the Arctic in spring 2000 as part of the FIRE-ACE/SHEBA field project (Curry et al. 2000).

Aitken nucleus concentrations (defined here as the total concentration of particles with diameters between about $0.02-0.3 \mu \mathrm{m}$ ) were measured aboard the UW Convair-580 using a TSI condensation nucleus counter (Model 3760). The TSI 3760 uses a laser diode optical particle counter that measures the total number concentration of particles with sizes larger than $0.01 \mu \mathrm{m}$ diameter, but because of the design of the inlet to this counter particles larger than about $0.3 \mu \mathrm{m}$ diameter were not measured. The inlet to the TSI 3760 on the Convair-580 is designed to remove cloud droplets from the air flow into the laser cavity by passing the air flow through a cyclone separator. The separator removes droplets larger than $5 \mu \mathrm{m}$ diameter from the air flow via impaction, leaving just cloud interstitial aerosol for detection by the TSI 3760 . Weber et al. (1998) suggested that spuriously high concentrations of Aitken nuclei might be measured from an aircraft flying in clouds due to the fragmentation of cloud drops in aerosol inlets. There is no evidence that this occurred in the measurements described here, indeed, just the contrary. In 
ascent-descent "porpoise" maneuvers in and out of cloud top, there were no significant changes in Aitken nucleus concentrations.

A Particle Measuring Systems (PMS) PCASP-100X instrument was used to measure size distributions of particles from 0.1 to $3 \mu \mathrm{m}$ diameter. The PCASP was routinely calibrated with glass beads and latex spheres. The PCASP dries the sampled aerosol by heating the airstream $\sim 10-15^{\circ} \mathrm{C}$ before sampling. However, within clouds, droplets are only partially evaporated by the PCASP, therefore the remnants of cloud droplets may artificially enhance the measured concentrations of particles in the tail $(>1 \mu \mathrm{m}$ diameter) of the aerosol spectrum. For this reason, we neglected the contributions that particles $>1 \mu \mathrm{m}$ diameter made to the total particle concentrations measured by the PCASP in clouds.

A PMS FSSP-100 forward-light scattering instrument was used to measure particles and droplets from 2 to $47 \mu \mathrm{m}$ diameters. The total surface area of particles (and droplets in clouds) was derived from the PCASP and FSSP-100 measurements assuming spherical particles. The estimated uncertainty in the surface area measurements is $\pm 15 \%$ within cloud and $\pm 50 \%$ out of cloud.

The water vapor mixing ratio was measured with an Ophir Corp. Model IR-2000 infrared optical hygrometer. This instrument uses the differential water vapor absorption between two beams, one absorbing $(2.665 \mu \mathrm{m})$ and the other non-absorbing $(2.45 \mu \mathrm{m})$, to directly measure the density of water vapor. The instrument operates at a frequency of $20 \mathrm{~Hz}$ with a resolution of better than $1 \%$ for water vapor contents greater than $2 \mathrm{~g} \mathrm{~m}-3$. A reverse-flow inlet is used to prevent liquid water from entering the instrument. However, both beams are absorbed equally by any liquid water that might enter the instrument. Cerni (1994) provides details on the Ophir instrument, which we have used successfully for airborne measurements for many years (e.g., Perry and Hobbs 1996). 


\section{Results}

In middle latitudes the cloud-topped marine boundary layer is generally capped by an increase in temperature (i.e., a temperature inversion) and a decrease in dewpoint (Fig. 1a). The Arctic is unusual in that quite frequently both temperature and humidity increase with height over distances of several hundreds of meters above the tops of low-level stratus clouds (Fig. 1b).

Increases in humidity above arctic stratus clouds were observed frequently aboard the UW Convair-580 research aircraft during the FIRE-ACE/SHEBA field study. Between May 20 and June 24, 2000, 47 vertical profiles of stratus clouds were made in twenty-three flights. Twenty-seven of these profiles were characterized by increases in humidity over distances of several hundred meters just above the cloud-topped boundary layer, with the water vapor mixing ratio $\sim 1-2 \mathrm{~g} / \mathrm{kg}$ higher within these regions than in the boundary layer. In each of these 27 cases, there was a significant increase in Aitken nucleus concentrations within the zone of high humidity. In 18 of the remaining 20 cases where there was not an increase in humidity above cloud top, there was also not an increase in Aitken nuclei. In the two cases where there was an increase in Aitken nuclei above cloud top in the absence of an increase in humidity, the lightscattering coefficient (indicative of larger particles) was also elevated. This suggests that in these two cases both small and larger particles were enhanced by the (coincidental) occurrence of an arctic haze layer near cloud top.

Figure 2 shows three examples of large increases in Aitken nucleus concentrations above the tops of arctic stratus clouds. The most frequently observed scenario was similar to that shown in Fig. 2(i). Here the Aitken nucleus concentration is highest in the temperature inversion immediately above cloud top, where the Aitken nuclei are highly correlated with the water vapor mixing ratio. Since there was not a significant increase in the concentration of particles $>0.1 \mu \mathrm{m}$ diameter just above cloud top, the increase in Aitken nuclei was due to enhanced concentrations of particles $<0.1 \mu \mathrm{m}$ diameter. A similar scenario is shown in Fig. 2(ii), where the Aitken nuclei are again well correlated with the water vapor mixing ratio, particularly between 0.2 and $0.8 \mathrm{~km}$ in altitude. 
Figure 2(iii) shows another case where high Aitken nucleus concentrations were present above cloud top. In this case, however, the water vapor mixing ratio increased steadily with altitude, rather than attaining a local maximum above cloud top.

Figure 3 shows three cases where high Aitken nucleus concentrations were not observed above cloud top. In each of these three cases, the water vapor mixing ratio was significantly lower than those measured near cloud top for the three cases shown in Fig. 2 where elevated Aitken nucleus concentrations were observed.

\section{Discussion}

The mechanism that has been most commonly proposed to explain the occurrence of high concentrations of small particles in humid air is homogeneous-bimolecular nucleation (HBN) of sulfuric acid solution droplets from $\mathrm{H}_{2} \mathrm{SO}_{4}$ and $\mathrm{H}_{2} \mathrm{O}$ vapor (e.g., Itoh et al. 1977; Middleton and King 1978; Roedel 1979; Shaw 1989; Hegg et al. 1990; Raes et al. 1993; Perry and Hobbs 1994; Saxena and Grovenstein 1994). The measurements that we obtained in the Arctic are not sufficient to determine whether HBN, or other possible mechanisms, were responsible for the high particle concentrations above cloud tops since, apart from $\mathrm{H}_{2} \mathrm{O}$ vapor, we did not measure the relevant chemical species. However, the physical conditions under which the high particle concentrations occurred are, in general, consistent with HBN. For example, HBN theory predicts that new particle formation is favored by high humidities, low temperatures, a small pre-existing surface area of particles, and high actinic flux: conditions that are common above arctic stratus clouds in spring and summer.

Specifically, Fig. 2(i) and (ii) show high correlations between Aitken nucleus concentrations above cloud top and the water vapor mixing ratio. In Fig. 2(iii), the Aitken nucleus concentrations above cloud top peak in a region of increasing water vapor mixing ratio, but then decrease with increasing altitude above about $0.15 \mathrm{~km}$, even though the water vapor mixing ratio continues to increase. In terms of $\mathrm{HBN}$ theory this could be due to the continual increase of temperature with height shown in Fig. 2(iii). In Fig. 2(i) and 2(iii) the surface areas of 
the particles are small $\left(\sim 100 \mu \mathrm{m}^{2} \mathrm{~cm}^{-3}\right)$ in the regions where the Aitken nucleus concentrations peak. However, Fig. 2(ii) shows a layer of high Aitken nucleus concentrations within the upper $200 \mathrm{~m}$ of the cloud layer itself, where particle surface area concentrations were $\sim 50,000 \mu \mathrm{m}^{2} \mathrm{~cm}^{-3}$ (due mainly to supermicron cloud droplets). This is difficult to explain in terms of HBN theory, since high particle surface areas provide a large sink for $\mathrm{H}_{2} \mathrm{SO}_{4}$ vapor and therefore limits the nucleation of new particles. However, 5 min prior to the measurements shown in Fig. 2(ii), the cloud top was $200 \mathrm{~m}$ lower (at $0.3 \mathrm{~km}$ ). Therefore, the high Aitken nucleus concentrations shown in Fig. 2(ii) could have formed in the humidity inversion prior to the formation of cloudy air in the moist layer between 0.3 and $0.5 \mathrm{~km}$.

In the cases where Aitken nucleus concentrations were not noticeably enhanced above cloud tops (Fig. 3), the water vapor was significantly lower than those measured near cloud top where elevated Aitken nucleus concentrations were measured (Fig. 2). It appears therefore that enhanced humidities are crucial for the formation of high particle concentrations above cloud tops in the Arctic.

Regardless of the mechanism(s) responsible for high Aitken nucleus concentrations above cloud tops, the measurements reported here show that this phenomenon is common above the tops of arctic stratus clouds in spring. Since stratus clouds are ubiquitous in the Arctic, this could be a widespread source of small particles in this region.

Acknowledgments. This research was supported by NASA grants NAG1-2079, NCC5-326, NAS1-18940 and NAG5-7675.

\section{REFERENCES}

Cerni, T.A., 1994: An infrared hygrometer for atmospheric research and routine monitoring. $J$. Atmos. Oceanic Technol., 11, 445-462.

Curry, J. A. et al., 2000: FIRE arctic clouds experiment. Bulletin Amer. Meteor. Soc., 81, 5-29. 
Hegg, D.A., L.F. Radke, and P.V. Hobbs, 1990: Particle production associated with marine clouds. J. Geophys. Res., 95, 13 917-13 926.

Hudson, J.G., 1993: Cloud condensation nuclei near marine cumulus. J. Geophys. Res., 98, 26932702. , and P.R. Frisbie, 1991: Cloud condensation nuclei near marine stratus. J. Geophys. Res., 96, $20795-20808$.

Itoh, M., K. Takahashi, and M. Kasahara, 1977: The temperature dependence of nucleation of sulfuric acid-water mixture in air. J. Aerosol Sci., 8, 183-189.

Middleton, P., and C. S. Kiang, 1978: A kinetic aerosol model for the formation and growth of secondary sulfuric acid particles. J. Aerosol Sci., 9, 359-385.

Perry, K.D., and P.V. Hobbs, 1994: Further evidence for particle nucleation in clear air adjacent to marine cumulus clouds. J. Geophys. Res., 99, 22 803-22 818. , and __ 1994: Influences of isolated cumulus clouds on the humidity of their surroundings. J. Atmos. Sci., 40, 159-174.

Radke, C.F., and P.V. Hobbs, 1991: Humidity and particle fields around some small cumulus clouds. J. Atmos. Sci., 48, 1190-1193.

Raes, F., R. van Dingenen, J. Wilson, and A. Saltelli, 1993: Cloud condensation nuclei from dimethylsulfide in the natural marine boundary layer: Remote vs. in situ production. Dimethylsulfide Oceans, Atmosphere and Climate, G. Restelli and G. Angeletti, Eds., Kluwer Academic Pub., 311-322.

Roedel, W., 1979: Measurement of sulfuric acid saturated vapor pressure: Implications for aerosol formation by heteromolecular nucleation. J. Aerosol Sci., 10, 375-380.

Saxena, V.K., and J.D. Grovenstein, 1994: The role of clouds in the enhancement of cloud condensation nuclei concentrations. Atmos. Res., 31, 71-89.

Shaw, G.E., 1989: Production of condensation nuclei in clean air by nucleation of $\mathrm{H}_{2} \mathrm{SO}_{4}$. Atmos. Env., 23, 2841-2846. 
Weber, R.J., A.D. Clarke, M. Litchy, J. Li, G. Kok, R.D. Chillawski, and P.H. McMurray, 1998: Spurious aerosol measurements when sampling from aircraft in the vicinity of clouds. $J$. Geophys. Res., 103, 28 337-28 346. 


\section{FIGURE CAPTIONS}

FIG. 1. Schematics of typical profiles of temperature $(T)$ and dewpoint $\left(T_{d}\right)$ above stratus clouds in (a) mid-latitudes, and (b) in the Arctic.

FIG. 2. Three examples of elevated Aitken nucleus concentrations above the tops of arctic stratus clouds. The panels marked (a) on the left-hand side show vertical profiles of water vapor mixing ratio (dashed line) and temperature (solid line). The panels marked (b) on the right-hand side show vertical profiles of Aitken nucleus concentrations (solid line), particle concentrations in the accumulation mode (dashed line), and the surface area of the hydrated particles (dotted line). The shaded region represents stratus cloud.

FIG. 3. Three examples where elevated Aitken nucleus concentrations were not observed above the tops of arctic stratus clouds. See caption to Fig. 2 for legend. 

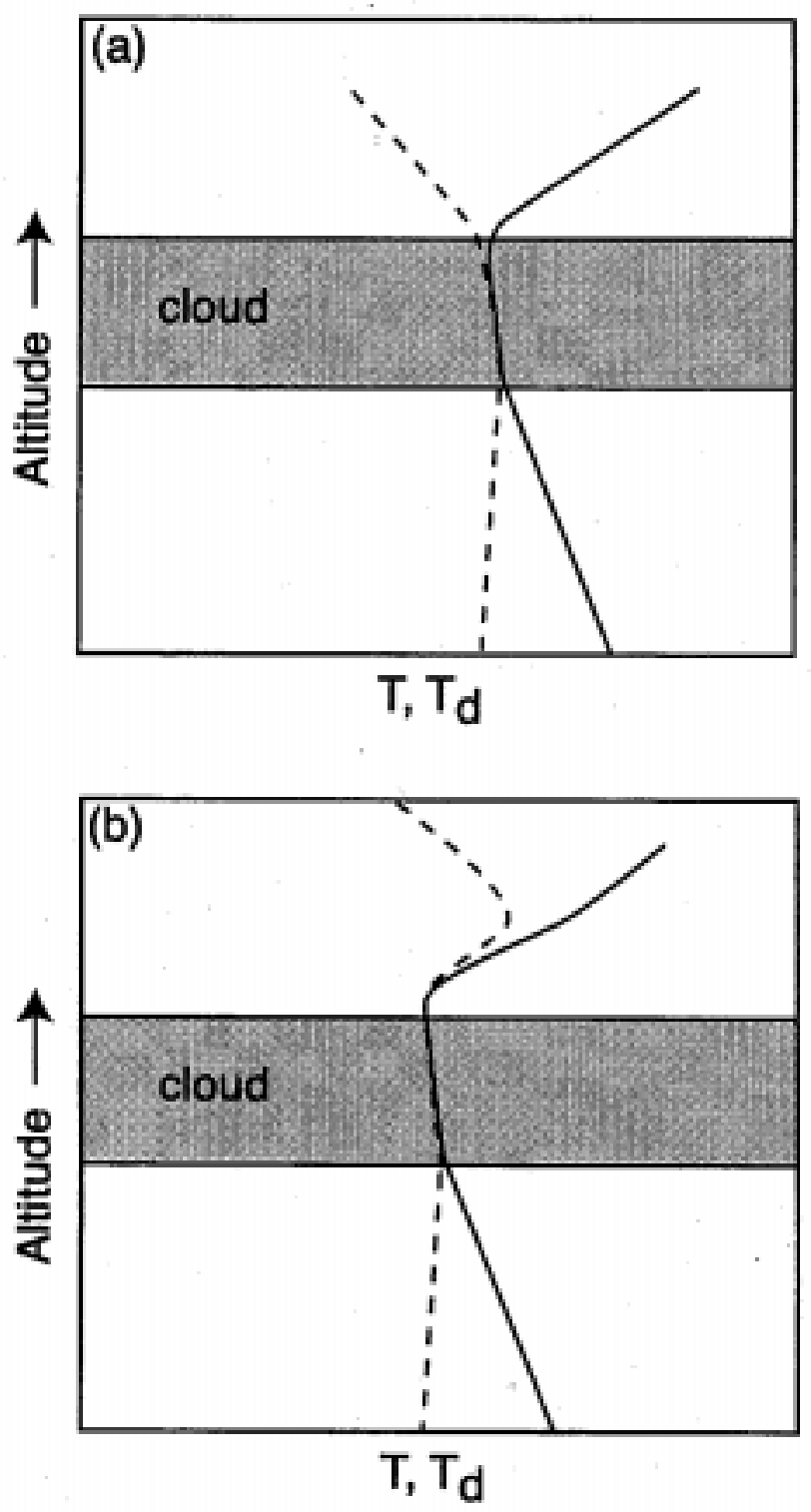

Garrett et al.

Figure 1 
Garrett et al.

F1gure 2

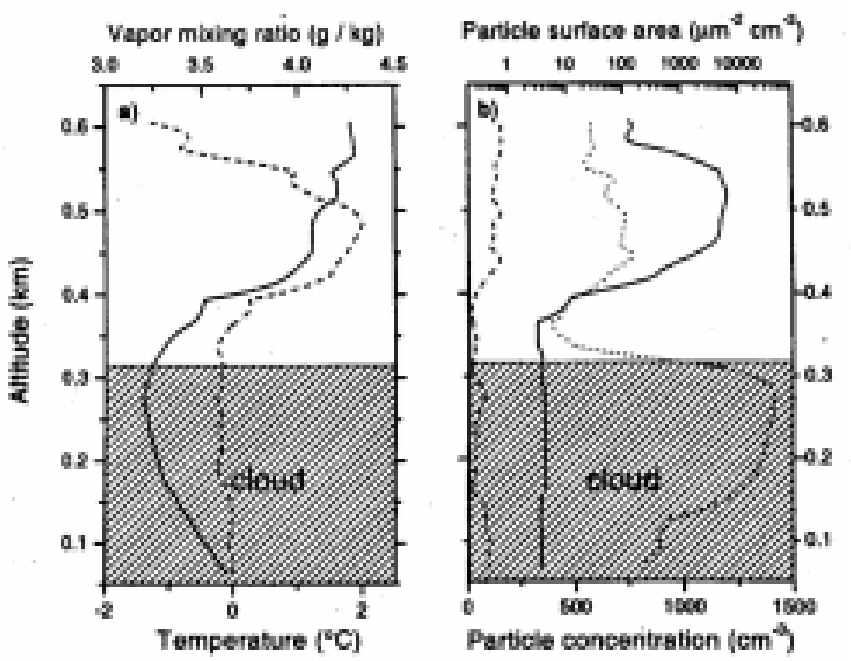

(i) 2040 UTC June 14
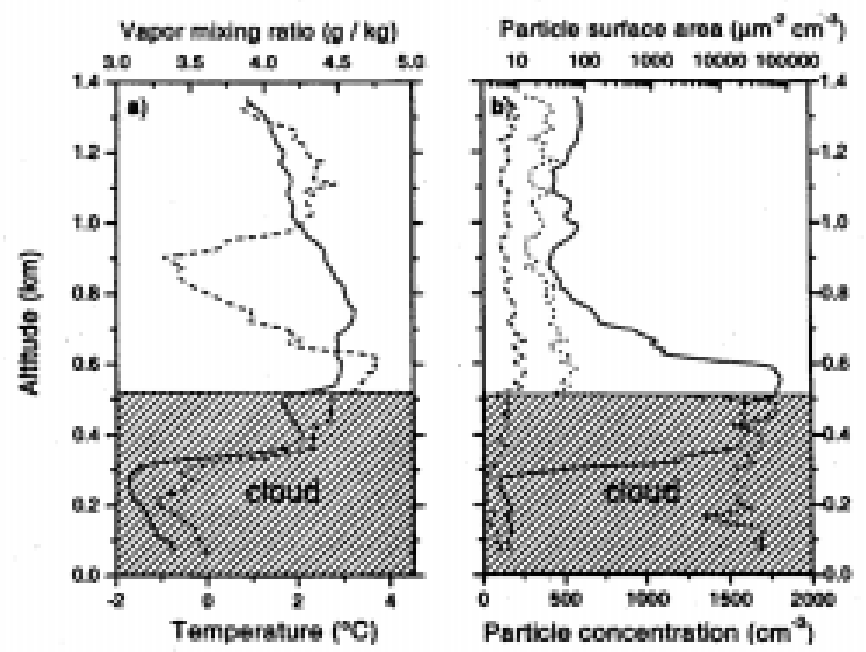

(ii) 2230 UTC June 5
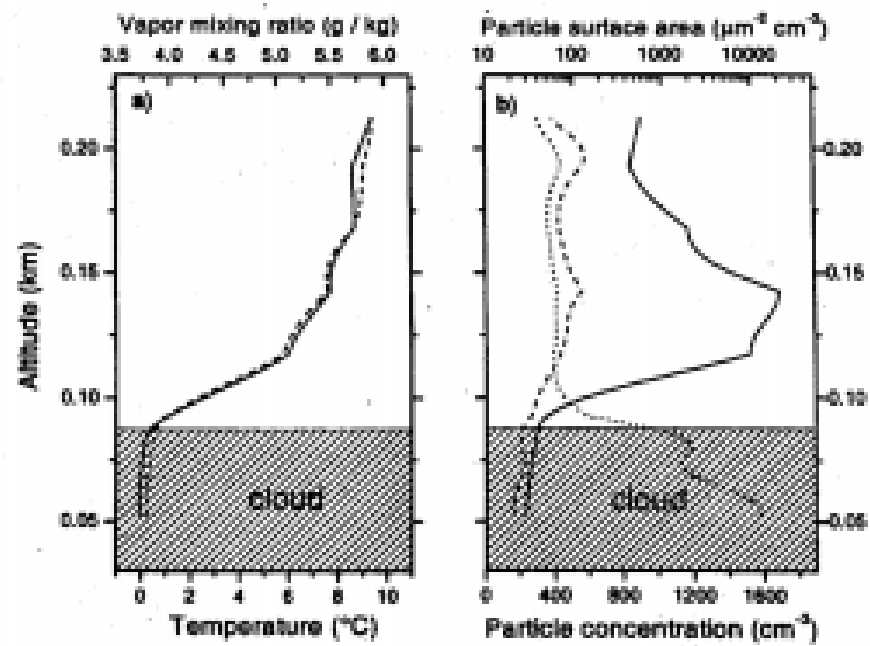

(ii) 2040 UTC May 28 
Garrett et al.

F1gure 3

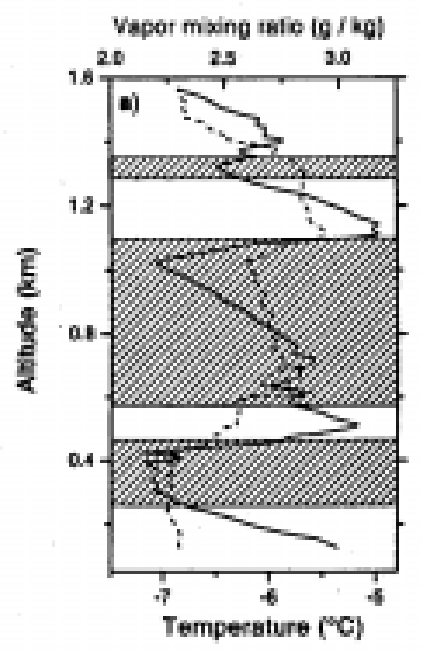

Particle surtece aroo $\left(4 \mathrm{~m}^{4} \mathrm{~cm}^{3} \mathrm{3}\right.$

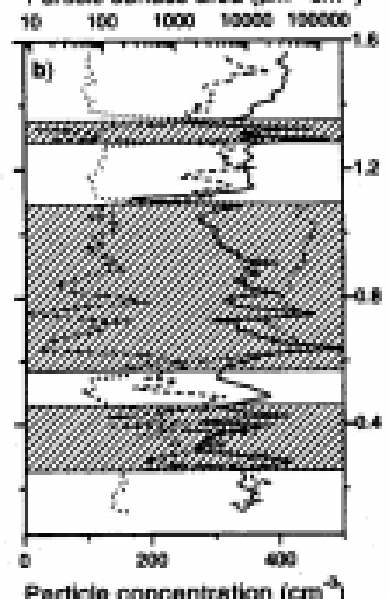

(6) 2050 UTC Mey 21

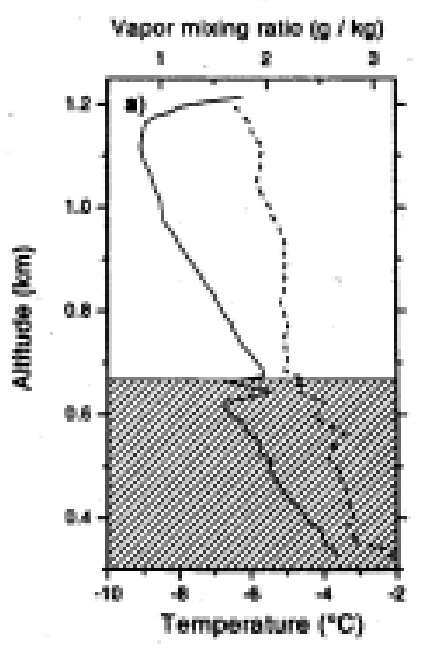

Particlo wurtace ares $\left(\mathrm{mm}^{-4} \mathrm{~cm}^{-1}\right)$

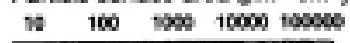

(ii) 2210 UTC June 9

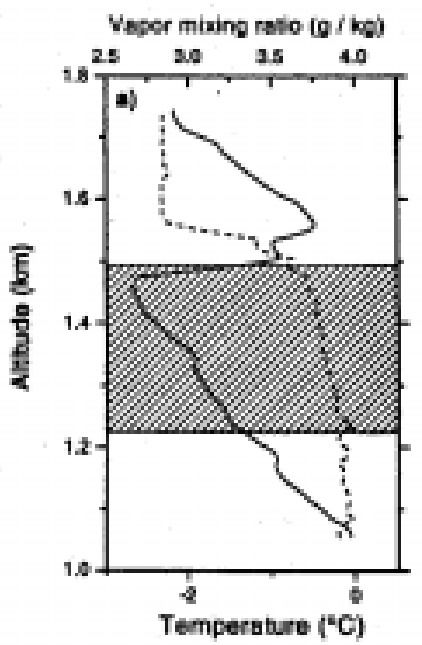

Particis surface area $\left(\mu \mathrm{m}^{2} \mathrm{~cm}{ }^{3}\right)$ $10 \quad 160 \quad 1000 \quad 16060 \quad 1606000$

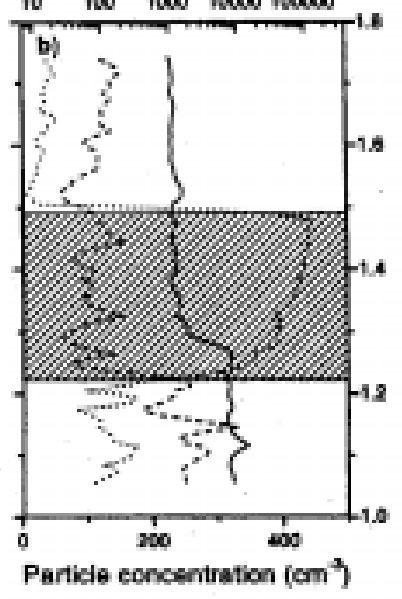

(ii) 2010 UTC June 13 